\title{
A Saudi family with sickle cell disease presented with acute crises and COVID-19 infection, a case report
}

\author{
ABDULQADER AL-HEBSHI ${ }^{1}$, Mohammed Zolaly ${ }^{2}$, Amer Alshengeti ${ }^{2}$, Ghaya Al \\ Qurainees $^{1}$, Sofyan Yamani ${ }^{1}$, Naif Hamdan ${ }^{1}$, and Turki Alwasaidi ${ }^{2}$ \\ ${ }^{1}$ National Guard Health Affairs \\ ${ }^{2}$ Taibah University College of Medicine
}

June 8, 2020

\begin{abstract}
Severe acute respiratory syndrome coronavirus 2 (SARS-CoV-2) has emerged as a new infectious agent causing the ongoing coronavirus disease 2019 (COVID-19) pandemic since December 2019. The most severe disease and mortality due to COVID19 occur in patients with comorbidities. Sickle cell disease (SCD) patients are considered immunocompromised due to the loss of splenic function. Here we report three cases of COVID-19 in one family affected by SCD. A mother and two siblings were diagnosed with COVID-19. The two siblings, 14 and 12 years, presented with vaso-occlusive crisis and one subsequently developed acute chest syndrome (ACS). All family members had favorable outcomes.
\end{abstract}

\section{Key words}

COVID-19; sickle cell anemia; acute chest syndrome; vaso-occlusive crisis

\section{Introduction}

Coronaviruses are positive-stranded RNA viruses with approximately $30 \mathrm{~kb}$ genome, surrounded by a protein envelope. [1]. Severe acute respiratory syndrome coronavirus 2 (SARS-CoV-2) has emerged since December 2019 causing the ongoing coronavirus disease 2019 (COVID-19) pandemic [2,3].

Evidence about COVID-19 in children is evolving but many questions are still unanswered in the pediatric population. According to a systematic review, children represent $1 \%$ to $5 \%$ of all confirmed COVID-19 cases $[4,5]$. Most pediatric infections occur in family clusters with household contact [5]

Sickle cell anemia (SCA) patients are relatively immunocompromised compared to the normal population, mainly because of the loss of splenic functions [6]. Infections, including viral infections, are one of the triggers of a vaso-occlusive crises and acute chest syndrome (ACS) [7,8]. At the time of writing this report, COVID-19 presentation and outcomes in SCD have not been reported in In the Kingdom of Saudi Arabia (KSA). Here we are reporting three cases affected by SCD, a mother and two siblings, with COVID-19.

\section{The cases:}

\section{Case 1:}

A 14-year-old Saudi girl, known to have SCA, presented to the Emergency Department (ED) on April 11, 2020 with multi-focal body pain, more in the arms and legs for one day. There was no respiratory symptoms or fever. Other systemic symptoms were unremarkable. She has a past history of recurrent multiple vasoocclusive crises. Her current therapy is Hydroxyurea $1500 \mathrm{mg}$ once daily $(30 \mathrm{mg} / \mathrm{kg} /$ day) and folic acid supplement. 
On physical examination, she was in moderate to severe pain without respiratory distress. Vital signs showed oxygen saturation $99 \%$ at room air, heart rate $95 /$ minute, temperature $38.5 \mathrm{OC}$ (once), respiratory rate $20 \mathrm{breath} /$ minute and blood pressure 121/61 mmHg. A systemic examination showed generalized mild tenderness in both thighs and arms. Other systemic examinations were unremarkable.

Her complete blood count was normal except anemia Hemoglobin level was 88gm/L and leukocytosis 16.2 (normal 5-12 × 109 cells/L) The C-reactive protein (CRP) was normal with a value of $3.2 \mathrm{mg} / \mathrm{L}$. As the patient is living in Al-Madinah, an endemic city for COVID-19 since late March 2020, SARS-CoV-2 real time polymerase chain reaction (RT-PCR) was requested and was positive. However, there was no history of family contact with COVID-19 patients.

The patient was managed as multifocal vaso-occlusive crisis (VOC) to rule out sepsis. She received intravenous (IV) fluid and IV morphine as well as ceftriaxone till negative blood cultured confirmed. She was monitored for 10 days and fortunately she remained afebrile and vitally stable. The chest x-ray was normal with no evidence of infiltrate.

She did not receive any antiviral for COVID-19. Her VOC symptoms improved and resolved completely on Day 6 of admission. A second nasopharyngeal swab for SARS-CoV-2 PCR remained positive for 10 days. Third swab was negative after 2 weeks.

\section{Case 2:}

A 12-year-old boy, the younger brother of Case 1 and also known to have SCA, presented 6 days after Case 1 with back pain for 1 day. There was no fever on presentation. The rest of the history of the present illness was unremarkable. He had a past history of a splenectomy, a year ago, due to recurrent sequestration crises. His current treatment is hydroxyurea $1500 \mathrm{mg} / 1000 \mathrm{mg}$ alternating once daily $(35 \mathrm{mg} / \mathrm{kg} /$ day $)$.

His examination showed temperature $36.6{ }^{\circ} \mathrm{C}$, respiratory rate 24 /minute, oxygen saturation $96 \%$ on room air, heart rate $110 /$ minute, and blood pressure $121 / 77$. The systemic examination including the back was normal.

His complete blood count was normal except anemia Hemoglobin level was $8.8 \mathrm{gm} / \mathrm{dL}$ and leukocytosis 23.4 (normal 5-12 × 109 cells/L) CRP was $17.7 \mathrm{mg} / \mathrm{L}$ (normal value: $0.00-5.00 \mathrm{mg} / \mathrm{L}$ ). The chest x-ray was normal on admission.

He was admitted as VOC with suspected COVID-19, based on the exposure. On day 2 of admission, he developed fever $\left(39.3{ }^{\circ} \mathrm{C}\right)$ with hypoxia; Spo2 was $88 \%$ on room air. A repeated chest x-ray showed new infiltration with a suspicion of ground glass appearance opacity (Fig. 1). Ceftriaxone and azithromycin was prescribed for possible acute chest syndrome (ACS) with $2 \mathrm{~L} / \mathrm{min}$ oxygen by nasal cannula. The inflammatory markers were worsening. The trend of WBC, CRP, Ferritin and F-Dimer is shown in (Table. 1). SARSCoV-2 RT-PCR was positive, and the respiratory viruses multiplex PCR was not negative. The antibiotics were upgraded to Meropenem and Vancomycin for possible severe pneumonia with ACS. He received blood transfusion on Day 3 of admission and dexamethasone $0.3 \mathrm{mg} / \mathrm{kg} / \mathrm{dose} \mathrm{q} 12$ hours for 3 days. On Day 2 of admission, hydroxychloroquine was prescribed, as recommended by the Saudi MOH guideline, at a dose of $6.5 \mathrm{mg} / \mathrm{kg}$ the first day, then $3.5 \mathrm{mg} / \mathrm{kg}$ for of 5 days.

He improved gradually and the oxygen supply was discontinued on Day 4 of admission. He completed 10 days of antibiotics, including 5 days of azithromycin and hydroxychloroquine. Repeated SARS-CoV-2 PCR remained positive for 12 days with the last test done on April 27, 2020.

\section{Case 3:}

A 50-year-old female, known to have a sickle cell trait and the mother of Cases 1 and 2. She was tested for SARS-CoV-2 PCR based on the history of exposure to her son and daughter. She had no significant symptoms except headache and generalized fatigability for one week prior to testing on 24 April, 2020. The SARS-CoV-2 PCR was positive. Her examination, laboratory investigation and chest x-ray were normal. She remained asymptomatic 


\section{Discussion:}

To the best of our knowledge, this is the first report of SCA patients infected with COVID-19 in KSA. The symptoms were mild in the mother, a carrier of the SC trait. VOC in the older sister was treated according to standard practice with no antiviral or anti-inflammatory treatment.

The second case presented with VOC and developed symptoms of COVID-19 pneumonia which coincided with the ACS symptoms.

Since April 17, 2020, no drug with proven efficacy has been identified for SARS-CoV-2. We treated the patient according to the national guidelines for COVID19 and as ACS [9].

Hydroxychloroquine displays in vitro antiviral and immunomodulatory activity [10]. A recently published observational study with a cohort of 166 patients from 18 to 85 years, hospitalized due to COVID-19, indicated that hydroxychloroquine treatment increased the cumulative mean survival, according to the diagnosis of severity at the beginning, by 1.4 to 1.8 times. This difference was statistically significant when the clinical picture at admission was mild [11]. However, better evidence from a highly powered randomized control trial (RTC) is still lacking.

It is not recommended to use corticosteroid for COVID-19, based on an early observational study from China and previous experience with other viral infections including influenza and MERS-CoV [12,13]. However, dexamethasone was started for Case 2 based on the possibility of ACS. Though the benefit of corticosteroid in ACS in controversial, a RCT in children with mild and moderate ACS showed that a short course of improved clinical outcomes, the need for blood transfusion and a reduced length of hospital stay [14].

The pathogenesis of both ACS and COVID-19 pneumonia is characterized by sever inflammatory response. $[15,16]$. Interleukine- 6 has been found high in patients with COVID-19, but not in ACS patients [15, 17]. De Luna et al. reported a case of a 45-year-old male who presented with VOC associated with COVID-19 and progressed to severe ACS. He was treated with hydroxychloroquine and Tocilizumab, a monoclonal antibody that acts as an IL-6 receptor antagonist. There was clear improvement of the patient's respiratory and general condition. [18].

\section{Declaration of Conflicting Interests}

All authors declare that they have no conflict of interest or sources of fund.

\section{Ethical issues}

Ethical and scientific approval was received from the Institutional Review Board (IRB) of King Abdullah International Medical Research Center, Riyadh, Saudi Arabia.

\section{References:}

1. Shi Z, Hu Z. A review of studies on animal reservoirs of the SARS coronavirus. Virus Res 2008; 133: 74-87.

2. Wu P, Hao X, Lau EHY, et al. Real-time tentative assessment of the epidemiological characteristics of novel coronavirus infections in Wuhan, China, as at 22 January 2020. Euro Surveill 2020; 25: 2000044.

3. https://www.who.int/docs/default-source/coronaviruse/situation-reports/20200420, accessed, May 9.2020 .

4. Ludvigsson, Jonas F. "Systematic review of COVID-19 in children show milder cases and a better prognosis than adults." Acta Paediatrica (2020).

5. COVID, CDC, et al. "Coronavirus Disease 2019 in Children-United States, February 12-April 2, 2020." Morbidity and Mortality Weekly Report 69.14 (2020): 422.

6. The spleen and sickle cell disease: the sick (led) spleen. Valentine Brousse, Pierre Buffet and David Rees. British Journal of Haematology, 2014, 166, 165-176

7. Hebbel, R. P., Visser, M. R., Goodman, J. L., Jacob, H. S., \& Vercellotti, G. M. (1987). Potentiated adherence of sickle erythrocytes to endothelium infected by virus. The Journal of clinical investigation, 
80(5), 1503-1506.

8. Vichinsky, E. P., Neumayr, L. D., Earles, A. N., Williams, R., Lennette, E. T., Dean, D., .. \& Daeschner, C. (2000). Causes and outcomes of the acute chest syndrome in sickle cell disease. New England Journal of Medicine, 342(25), 1855-1865.

9. Saudi MoH Protocol for Patients Suspected of/Confirmed with COVID-19 Supportive care and antiviral treatment of suspected or confirmed COVID-19 infection (version 1.4) April 12th, 2020

10. Yao, X., Ye, F., Zhang, M., Cui, C., Huang, B., Niu, P., .. \& Zhan, S. (2020). In vitro antiviral activity and projection of optimized dosing design of hydroxychloroquine for the treatment of severe acute respiratory syndrome coronavirus 2 (SARS-CoV-2). Clinical Infectious Diseases.

11. de Novales, F. J. M., Ramirez-Olivencia, G., Estebanez, M., de Dios, B., Herrero, M. D., Mata, T., ... \& Martinez, Y. (2020). Early Hydroxychloroquine Is Associated with an Increase of Survival in COVID-19 Patients: An Observational Study.

12. World Health Organization. Novel Coronavirus (2019-nCoV) technical guidance: Patient management. https://www.who.int/emergencies/diseases/novel-coronavirus-2019/technicalguidance/patient-management (Accessed on May 12, 2020).

13. Russell, C. D., Millar, J. E., \& Baillie, J. K. (2020). Clinical evidence does not support corticosteroid treatment for 2019-nCoV lung injury. The Lancet, 395(10223), 473-475.

14. Bernini, J. C., Rogers, Z. R., Sandler, E. S., Reisch, J. S., Quinn, C. T., \& Buchanan, G. R. (1998). Beneficial effect of intravenous dexamethasone in children with mild to moderately severe acute chest syndrome complicating sickle cell disease. Blood, The Journal of the American Society of Hematology, 92(9), 3082-3089.

15. Rothan, H. A., \& Byrareddy, S. N. (2020). The epidemiology and pathogenesis of coronavirus disease (COVID-19) outbreak. Journal of autoimmunity, 102433.

16. Melton, C. W., \& Haynes, J. (2006). Sickle acute lung injury: role of prevention and early aggressive intervention strategies on outcome. Clinics in chest medicine, 27(3), 487-502.

17. Naprawa, J. T., Bonsu, B. K., Goodman, D. G., \& Ranalli, M. A. (2005). Serum biomarkers for identifying acute chest syndrome among patients who have sickle cell disease and present to the emergency department. Pediatrics, 116(3), e420-e425.

18. De Luna, G., Habibi, A., Deux, J. F., Colard, M., d'Alexandry, D. O. A., Schlemmer, F., .. \& \& Michel, M. (2020). Rapid and Severe Covid-19 Pneumonia with Severe Acute Chest Syndrome in a Sickle Cell Patient Successfully Treated with Tocilizumab. American journal of hematology.

TABLE 1 case 2 the trend of WBC, CRP, ferritin and d-dimer

WBC: white blood cell; ANC: absolute neutrophil count; ALC: absolute lymphocyte count; Hb: hemoglobin; CRP: C-reactive protein

\begin{tabular}{lllllllll}
\hline Test & 16 April & 17 April & 19 April & 20 April & 21 April & 23 April & 25 April & 28 April \\
\hline WBC $\left(\times 10^{9}\right.$ cells/L) & 23.4 & - & 20.1 & 17.9 & 9.7 & 10.0 & 10.1 & 11.1 \\
ANC $\left(\times 10^{9}\right.$ cells/L) & 11.70 & - & 16.40 & 15.8 & 8.13 & 4.43 & 4.53 & 6.06 \\
ALC $\left(\times 10^{9}\right.$ cells/L) & 7.77 & - & 2.93 & 1.62 & 1.23 & 4.72 & 4.27 & 3.54 \\
Hb $(\mathrm{gm} / \mathrm{dl})$ & 8.4 & - & 7.5 & 9.2 & 8.7 & 11.9 & 12.9 & 12.1 \\
Platelet $\left(\times 10^{9}\right.$ cells/L) & 503 & - & 329 & 279 & 428 & 528 & 318 & 570 \\
CRP $(\mathrm{mg} / \mathrm{L})$ & 17.7 & - & 279.9 & 336.9 & 223.6 & 46.8 & 23.0 & 20.4 \\
Ferritin $(\mathrm{ug} / \mathrm{L})$ & - & 3735.0 & 3207.4 & - & 3211.6 & 1892.2 & 1657.8 & 1603.2 \\
D-Dimer $(\mathrm{mg} / \mathrm{L})$ & - & 14.97 & 20.98 & - & 6.34 & 9.31 & 7.11 & 5.06 \\
\hline
\end{tabular}

Figure 1 AP supine portable chest X-ray shows bilateral ground-glass opacification of both lung fields, no collapse or consolidation, no pneumothorax/pleural effusion, possible COVID-19 characteristics 


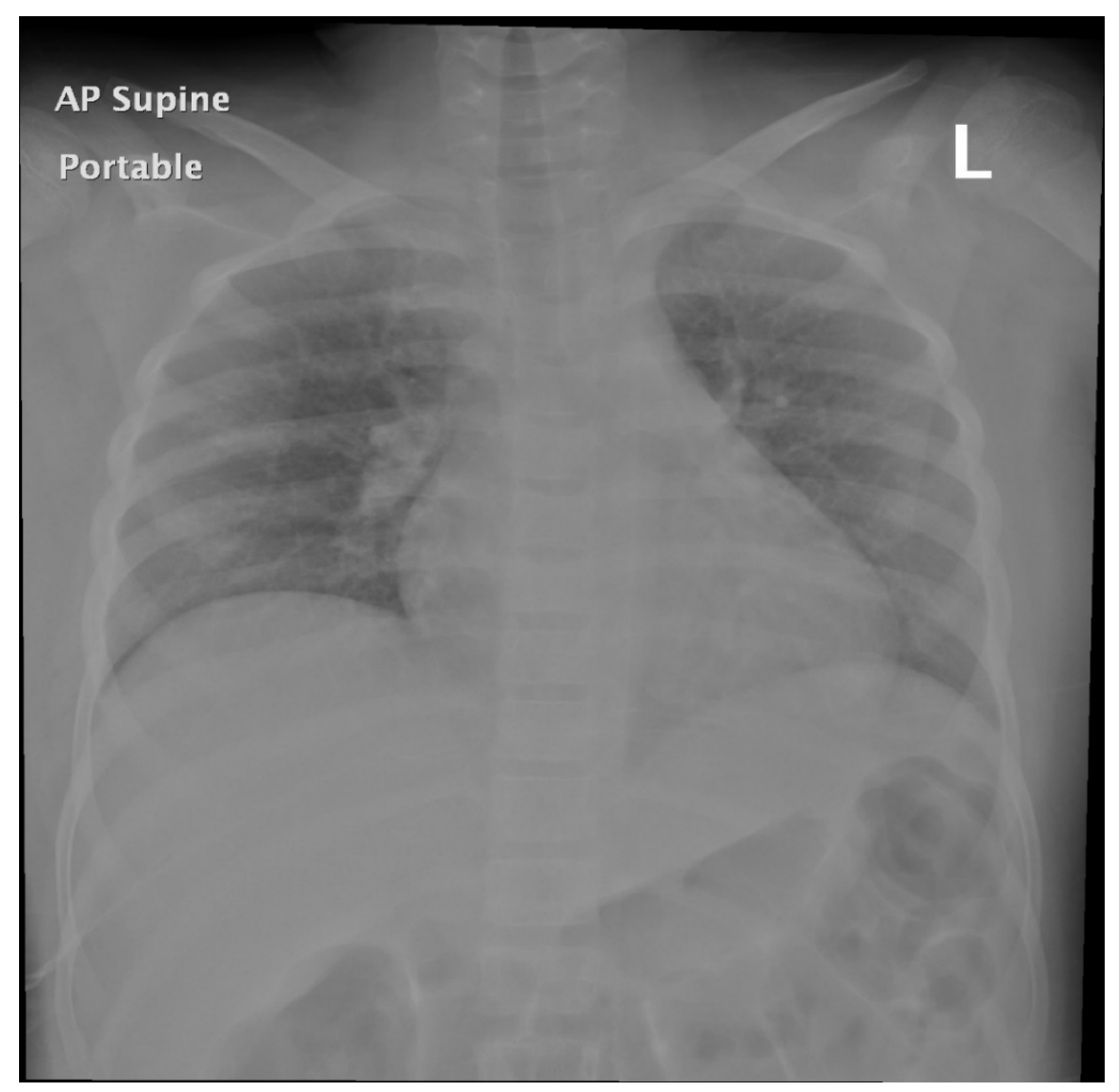

\section{Hosted file}

Table1.docx available at https://authorea.com/users/330875/articles/457689-a-saudi-familywith-sickle-cell-disease-presented-with-acute-crises-and-covid-19-infection-a-casereport 


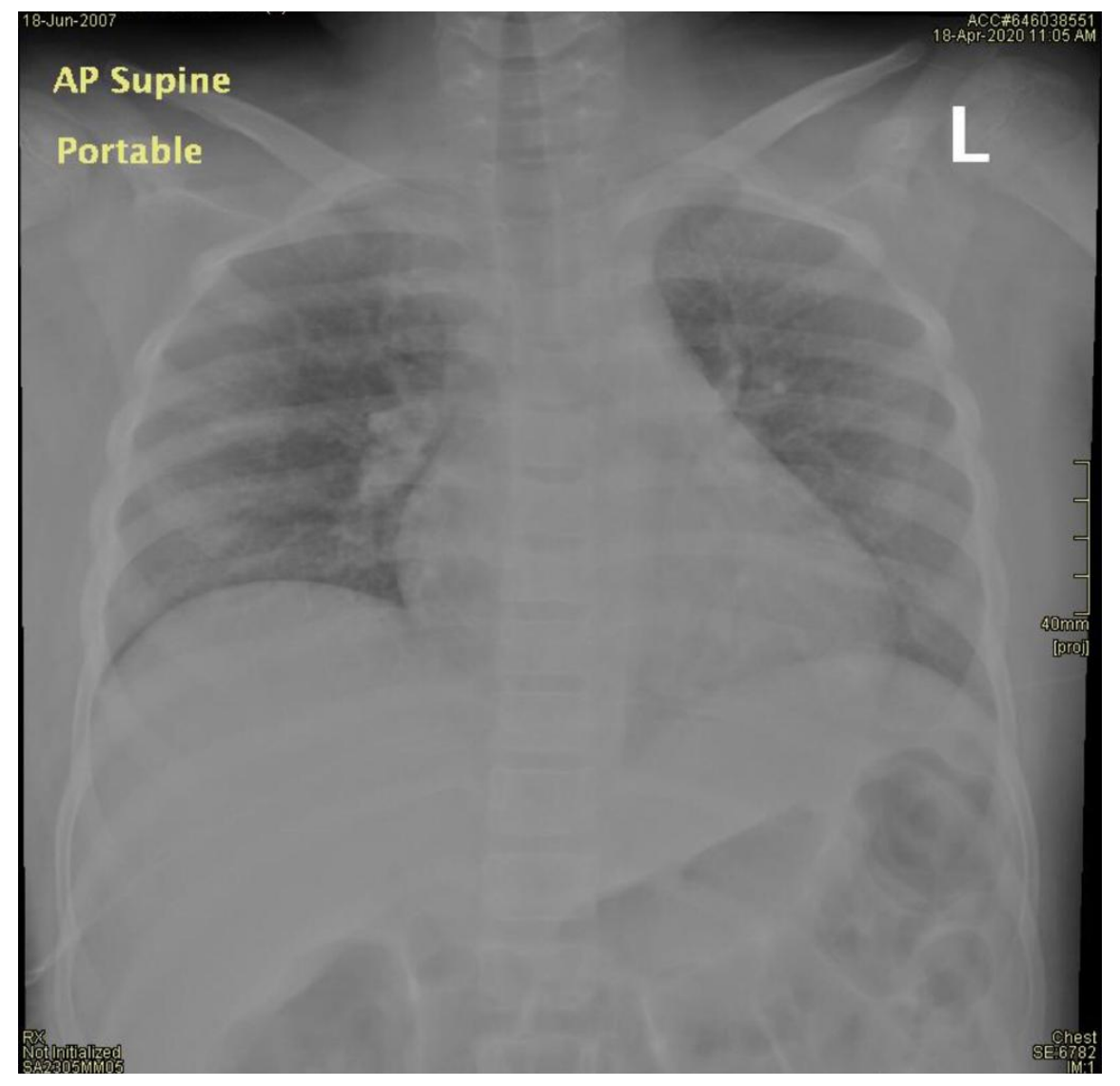

